\title{
The Subjectivity for Open Adoption of Nursing Students
}

\author{
Sunyoung Jang \\ Dept. of Nursing, Hanseo University, 46 Hanseol Ro, Haemi-myun, Seosan-si, \\ Chungcheongnam-do, 369-709, Korea \\ sjang@hanseo.ac.kr
}

\begin{abstract}
The purpose of this study is to identify the subjectivity of open adoption perceived by nursing students, describe the characteristics of each type and understand the typology about open adoption. Q methodology was applied for this study. 44 statements about open adoption were requested to classify targeting 25 students in $3 r d$ and 4 th grades who were practicing in A College Nursing Department. Collected data were analyzed using QUANL PC program. The results of this study showed that the perception about open adoption by nursing students is classified into 3 factors. The subjective types are 'social supportive', 'positive', and 'crisis coping'. This study provided the basic data on the perception and education about the open adoption of the nurses in the clinical practice.
\end{abstract}

Keywords: Open, Adoption, Nursing, Student, Subjectivity, Q methodology

\section{Introduction}

\subsection{Necessity of study}

As long as the adoption gives positive and desirable life satisfaction to the adopting family members, adopted child can achieve desirable cognitive, social, emotional and physical; development. In these meanings, the adoption form which is suggested by preceding studies as a plan to promote domestic adoption is open adoption. Therefore, the activation adoption plan for domestic adoption is aiming at open adoption. Open adoption has diverse and positive impacts on the adopting parents as well as the adopted child compared with confidential adoption [1][2][3][4], and also gives a positive effect to help birth parents as well as the adopted child and adopting parents to live and adapt to a better life as a member of the society. In addition, the study result that the satisfaction of open adoption is affected by adopted child, adopting parents and birth parents depending on the level of disclosure [5][6][7][8] shows that the complete open adoption most satisfies the adoption and provides useful information to derive the implication for the alternatives to practice the successful adoption culture.

Researches about open adoption targeting nursing college students are not sufficient. Therefore, Q methodology is an appropriate research method that each characteristic by type can be understood according to the subjective structure of the human beings and starts from the perspectives of the performer, not the researcher's family [9]. Therefore, this is an appropriate research method to identify the type of perception about open adoption of nursing

Article history:

Received (October 29, 2017), Review Result (December 29, 2017), Accepted (February 13, 2018) 
college students through Q methodology which is a research method considering the subjectivity of the subject.

Therefore, the purpose of this study is to identify the subjectivity structure of open adoption from the perspective of nursing college students and provide the basic data to develop the differentiated educational program depending on the type of characteristics of open adoption before the preliminary nurse advances to the nursing sites where the open adoption is successfully conducted.

\subsection{Purpose of study}

The purpose of this research is to study the subjective perception type and characteristics about open adoption of nursing college students using $\mathrm{Q}$ methodology, to provide the subjective perception type and characteristics by type of nursing college students who start open adoption and to provide the basic data to present the strategies for the education of the nursing students who start open adoption. Specific research purposes are as follows.

1) Characterize the subjective perception of nursing students about the open adoption.

2) Analyze and describe the characteristics of nursing students' perceptions by type about open adoption.

\section{Method of study}

\subsection{Design of study}

The purpose of this study was to identify the type of subjective perception of open adoption in nursing students who experienced open adoption after reviewing literature, media data and previous studies on open adoption.

\subsection{Q population and $Q$ sample selection}

To extract a comprehensive statement on the effect on open adoption, the Q population was derived from a review of domestic and foreign literature, an open questionnaire, and individual in-depth interviews focusing on current nursing students. Through this process, over 200 Q-populations from three domains were extracted, and in addition to that, by integrating the literature collected through the review of domestic and foreign literature, a total of $100 \mathrm{Q}$ populations were extracted. After reviewing and revising the extracted $\mathrm{Q}$ samples, the final 44 samples with high discriminative power were selected.

\subsection{Design of study}

The Q-methodology is not a personal difference but a qualitative research that emphasizes individual inertia by emphasizing differences in meaning or importance within an individual, and it is based on the small sample doctrine that when a P sample grows, several people are biased on one factor and their characteristics are not clearly revealed [10]. The P sample consists of a total of 25 students who are expected to participate in the study after fully explaining the purpose of the study to the students enrolled in the nursing department.

\subsection{Classification and data analysis method}

The $\mathrm{Q}$ classification process is a process by which individuals who are selected as a $\mathrm{P}$ sample classify the statement of the $\mathrm{Q}$ sample as a forced normal distribution method, thereby 
creating a spontaneous definition of the companion animal by each individual. We collected data by using the Q card for 25 students of OO College of Nursing. The time required for one subject to complete the Q classification was 30-45 minutes. The distribution of the $\mathrm{Q}$ sample was classified from the strong positive to the strong negative in order of the importance of the subjects' opinion. The statements on open adoption (Q1) were classified on a 12-point scale. Afterwards, the subjects were interviewed about the statements classified at the extremes. The Q factor analysis used the Principal Component Factor Analysis, varimax. The type classification was selected based on the Eigen value of 1.0 or more and the number of factors and the total explanatory variable. The collected data were scored from 1 to 15 , with the conversion scores assigned to each, focused on the card distributed by the $\mathrm{Q}$ sample distribution table. The assigned conversion scores were coded in the $\mathrm{Q}$ sample order and processed by the main factor analysis by the QUANL PC program. Analysis of the data was done by the QUANL PC program.

\subsection{Ethical considerations for the subject}

After a volunteer consent was obtained from the subjects before the study, we explained to the subject that they could stop at any time during the study. To respect the rights of the subjects and ensure the confidentiality of the subject's privacy and information, all of the information collected through this study is treated as anonymous in the whole process of the data analysis and coded with Q sorting.

\section{Result of study}

Table 1. Q-statements on new nurse images type of representative items and Z-scores. $(\mathrm{N}=25)$

\begin{tabular}{|c|c|c|c|c|}
\hline Factor & No & Description & Mean (SD) & Z-score \\
\hline \multirow{3}{*}{$\begin{array}{l}\text { Factor } 1 \\
(\mathrm{~N}=7)\end{array}$} & 44 & Government support is needed for open adoption. & $11.14(1.464)$ & 2.65 \\
\hline & 43 & $\begin{array}{l}\text { Variety of post-programs for open adoption hoped } \\
\text { to be developed. }\end{array}$ & $9.86(2.545)$ & 2.27 \\
\hline & 11 & $\begin{array}{l}\text { In case of medical problems with your child, you } \\
\text { can receive therapeutic treatment fairly and } \\
\text { squarely. }\end{array}$ & $9.14(2.911)$ & 1.83 \\
\hline \multirow{3}{*}{$\begin{array}{c}\text { Factor } 2 \\
(\mathrm{~N}=13)\end{array}$} & 25 & $\begin{array}{l}\text { You can build a stronger family even if you don't } \\
\text { have blood relationship. }\end{array}$ & $9.92(1.935)$ & 1.79 \\
\hline & 30 & $\begin{array}{l}\text { In case the child fully accepts the adoption, he or } \\
\text { she doesn't have shame. }\end{array}$ & $8.38(2.902)$ & 1.69 \\
\hline & 6 & You become positive about adoption. & $9.31(2.057)$ & 1.50 \\
\hline \multirow{3}{*}{$\begin{array}{l}\text { Factor } 3 \\
(\mathrm{~N}=5)\end{array}$} & 44 & Government support is needed for open adoption. & $11.20(0.837)$ & 2.58 \\
\hline & 43 & $\begin{array}{l}\text { Variety of post-programs for open adoption hoped } \\
\text { to be developed. }\end{array}$ & $10.40(1.673)$ & 2.29 \\
\hline & 42 & The child becomes a subject of curiosity. & $9.00(2.121)$ & 1.38 \\
\hline
\end{tabular}


The Q factor analysis of the subjectivity of open adoption using the QUANL pc program revealed three types.

Social supportive type: They think that open adoption is more desirable than closed adoption if domestic adoption should be selected as an alternative of overseas adoption, and if they could have more post-adoption programs and government support for open adoption, open adoption will gradually increase. Therefore, type 1 was named as 'social supportive type'.

Positive type: Parents could truly love and raise the adopted child like their own biological child, and the child could feel the adopting parents like real family and feel a deeper affection than their birth parents. Therefore, type 2 was named as a 'positive type'.

Crisis coping type: When the adopted child feel anxiety, the parents would try to give a sense of belonging and stability to become a family member and respect the child's words, and consequently, the child could establish his or her identity and values. Therefore, type 3 was called as a 'crisis coping type'.

\section{Discussion}

Results of this study showed that the type of subjectivity about open adoption perceived by nursing students was identified as 'social supportive type', 'positive type' and 'crisis coping type' and the characteristics by type will be discussed.

Type 1 subject in this study was a 'social supportive type'. They acknowledge the various forms of family in a situation where the concept of the family is gradually changing and they feel the need for the attention and supports from the neighbors about the adopting family that is difficult to be accepted in Korean society yet.

Type 2 subject is a 'positive type'. They think that open adoption has more advantages than closed adoption, and open adoption in Korean society will increase in the future. Open adoption is positively thought to have less difficulty which could occur to adopting family or adopted child than closed adoption.

Type 3 subject is a 'crisis coping type'. The subjects emphasized on forecasting the problems in the family that could occur due to the adoption and prepare for the plans to deal with the future.

Regarding the characteristics of each type, the types of open adoption were divided into three types: the type who thinks the social support is a priority for open adoption family, the type who thinks the advantage of open adoption is a priority, and the type who thinks the preparation is required to deal with the future crisis that could occur to the open adoption family.

This study about the subjectivity could be used as a basic data for the development of alternatives to revitalize the open adoption. In addition, it is expected that this study would be used as the basic data for the development of differentiated educational programs by presenting the nursing college students' subjective structure about the open adoption and characteristics by type.

However, there is a limit to generalize the study results because this research was conducted just targeting one college and the subjects could not be screened considering the influencing factors on the perception about open adoption. Therefore, further verification researches will be required through the Q-sample which has various backgrounds.

\section{Conclusion}

Using Q methodology, this study was conducted to study the nursing students' subjective perception about the adoption and to prepare for the basic data to find the activation plans for 
the open adoption based on subjective analysis data. Study results of this study was divided into 3 factors. The types of open adoption perceived by nursing students were 'social supportive', 'positive', and 'crisis coping' type.

This study provided the basic data which are required to introduce or apply the policies to activate future open adoption by typifying the subjectivity of nursing students about the open adoption. The types of nursing college students' perception about open adoption were analyzed and the characteristics were identified through this study. It is expected that an educational program considering the characteristics of each type will be developed.

In addition, qualitative study is suggested to conduct follow-up researches about type analysis and to identify various factors affecting the nursing of open adoption subjects by selecting the sample considering various factors.

\section{Acknowledgements}

This paper was written in 2018 under the financial support of Hanseo university in school research project.

\section{References}

[1] C. Baumann, "Examining where we were and where we are: Clinical issues in adoption 1985-1995," Child and Adolescent Social Work. vol.14, no.5, pp.313-334, (1997)

[2] M. Berry, "Adoptive parents' perceptions of, and comfort with, open adoption," Child Welfare. vol.72, no.3, pp.231-253, (1993)

[3] M. Berry, D. J. C. Dylla, R. P. Barth and B. Needell, "The role of open adoption in the adjustment of adopted children and their families," children \& Youth Services Review, vol.20, pp.151-171, (1998)

[4] H. E. Gross, "Variants of open adoptions: the early years," Marriage and Family Review, vol.25, pp.19-42, (1997)

[5] L. Cushman, D. Kalmuss, and P. Namerow, "Openness in adoption: experiences and social psychological outcoms among birthmothers,” Marriage and Family Review, vol.25, pp.7-18, (1997)

[6] J. Etter, "Levels of cooperation and satisfaction in 56 open adoptions," Child Welfare, vol.72, pp.257-267, (1993)

[7] H. E. Gross, "Open adoption: A research-based literature review and new date," Child Welfare, vol.77, pp.269-284, (1993)

[8] H. D. Kirk, "Adoptive Kindship: A modern institution in need of reforms," Toronto: Butterworth \& Co., (1985)

[9] W. Stephenson, Q-methodology, "Interbehavioral psychology and quantum theory," Psychol Record, vol.32, pp.235-248, (1982)

[10] S. M. Whang, S. W. You, J. Y. Kim and R. G. Kim, "Consumer types and cultural consumption characteristics of Korean society: Who spends for what reasons?" Journal of Human Subjectivity, vol.13, pp.25-39, (2006) 
The Subjectivity for Open Adoption of Nursing Students

This page is empty by intention. 